\title{
COVID-19 Pandemic: Response by Department of Community Medicine in a Medical College of Mumbai, India
}

\section{Gajanan Velhal ${ }^{1}$, Anuradha Kunal Shah ${ }^{2}$, Chinnu Sara Varughese ${ }^{3}$}

${ }^{1}$ Professor and Head, ${ }^{2}$ Assistant Professor, ${ }^{3}$ Junior Resident Community Medicine Department,

Seth G S Medical College \& KEM Hospital, Parel, Mumbai, India

Correspondence : Dr. Anuradha Kunal Shah, Email: anuradha.moha@gmail.com

\begin{abstract}
:
The role of community medicine in epidemiology and disease outbreaks is significant. Covid-19 pandemic was an opportunity to realize this potential.Here we present the role of Community Medicine department of a Medical College in Mumbai, which was a global hotspot for Covid -19. The responses were initiated in the first week of February, prior to the detection of the first case in the city. With the progression of the pandemic, the roles have changed and adapted accordingly. The activity of Community Medicine department is unique to this specialty and has provided a lifetime experience for its residents andfaculty.Our purpose here is to project the roles depicted in this model so that some of them can be followed by community medicine departments of other colleges and continued post-pandemic too.
\end{abstract}

Key words: Community Medicine, COVID 19, Pandemic

\section{Introduction:}

The term 'Community Medicine' initially appeared in American healthcare in 1920, which represented comprehensive healthcare of an individual. $^{[1]}$ Presently, the scope of community medicine seems to be in the grey area as it overlaps with public health and family medicine. ${ }^{[2]}$

In India, Community Medicine generally covers services in the field areas of rural and urban health centers, academic activities for medical students, run various specialized clinics (immunization, geriatric, under five, etc.) and screening OPDs. ${ }^{[3]}$

The role of community medicine in epidemiology and disease outbreaks is significant. Covid-19 pandemic was an opportunity to realize this potential.

\begin{tabular}{|l|l|}
\hline Quick Response Code & Access this article online \\
\hline & Website : \\
\cline { 2 - 2 } & www.healthlinejournal.org \\
\hline
\end{tabular}

\section{COVID-19 response:}

The first case of Covid-19 in Mumbai was reported on 11th March 2020. As per directives from the state, the first active response was screening of incoming passengers at International Airport, Mumbai, from 6th March 2020, in collaboration with other medical colleges. Thermal screening was done, travel history obtained and decision for home/ facility quarantine was taken. Anticipating huge traffic on the state emergency helpline number, the capacity was augmented. PG students and interns were deputed at the Disaster management cell for effective risk communication, with average of 2500 calls being attended daily. IEC activities had begun much earlier and are ongoing. Posters made by Patient Education Cell, presentations and demonstrations were being used for spreading

\section{How to cite this article :}

Velhal G, Shah A, Varughese C. Covid-19 Pandemic: Response by Department of Community Medicine in a Medical College of Mumbai, India. Healthline. 2021; 12(3):101-105. 
awareness in the community.As social distancing norms were put forth, there was a gradual shift to digital platform based IEC activities. CMEs were conducted in collaboration with other departments for all healthcare workers (HCWs) even before the first case was detected in the state. Trainings were conducted later in batches.

At first, PG students were shunted to a public infectious disease hospital earmarked to treat COVID-19 patients. At the parent institute, a $24 \times 7$ cold-cough-fever (CCF) screening OPD with a triage area for symptomatic patients was set up on 21st March in collaboration with other clinical departments. Fever screening and swab collection clinics, in collaboration with the Public Health Department, was started for symptomatic people in containment areas of the city on $5^{\text {th }}$ April. A team comprising Community Medicine specialists, microbiologists and a staff nurse were deployed per area. Three to four areas were covered per day and an average of 60-70 people was screened per area. Since the parent institute is catering to both COVID and non-COVID patients, a preliminary screening of HCWs was conducted for presence of co-morbidities and accordingly deployed for COVID and non-COVID duties. A contact tracing team was established in the department on 9th April, after report of first HCW COVID case on 8th April. The team traced contacts of positive cases telephonically, assessed them, and also arranged for their quarantine facility, transport, and testing. Over time, the contacts have reduced significantly. Responding to state government's policy for sending willing migrant workers back home during lockdown, a screening OPD was begun for providing them with fitness certificates. This facility has been extended for all those who want to travel within the state. As the city soon turned into a global hotspot, many COVID Care Centers (CCC) were created in the city and doctors from all specialties were working in isolation and quarantine wards/facilities in shift duties. Our department also set up a special counselling helpline for our HCWs, along with Department of Physiotherapy and Occupational therapy for answering queries of HCWs of our hospital. It receives a current average of 10-15 calls per day during working hours. On $16^{\text {th }}$ January, 2021, COVID-19 vaccination was also commenced according to the government rules and is ongoing. Research related to epidemiology of COVID-19 and its determinants have been taken up by the department.

Along with the 'COVID activities', the Department runs all its routine services. Manpower management was crucial to avoid interruption of routine services. Academic activities had to be suspended. Physical infrastructural changes had to be brought within the OPD premises adhering to social distancing norms. Patients with chronic illnesses were prescribed medications for a longer duration. Many doctors contracted COVID-19 infection and their contacts had to be quarantined, causing overburden on remaining working doctors. Working in PPE kits added to the fatigue. Hence, skill mixing was adopted, wherein PG students from other specialties were roped in for screening duties and COVID-19 ward duties to fill the gaps. Data management and documentation also required more time and manpower. The contact tracing team had to deal with uncertainties of quarantine periods and ever evolving guidelines. In situations where contact history was hidden, altered or unreliable, appropriate decision making was crucial. Convincing doctors to be quarantined was a challenge due to manpower shortage in their departments. Community-based research became difficult due to the need for social distancing. Doctors going into the community also had to do counselling for allaying fears of the people, while managing their own. Overall, it was a trying period, but a good learning experience.

\section{Discussion:}

Our department had initiated responses in the first week of February, prior to the detection of the first case in the city, and is continuing with modifications 
Figure 1: Covid-19 response model- Department of Community Medicine in a Medical College

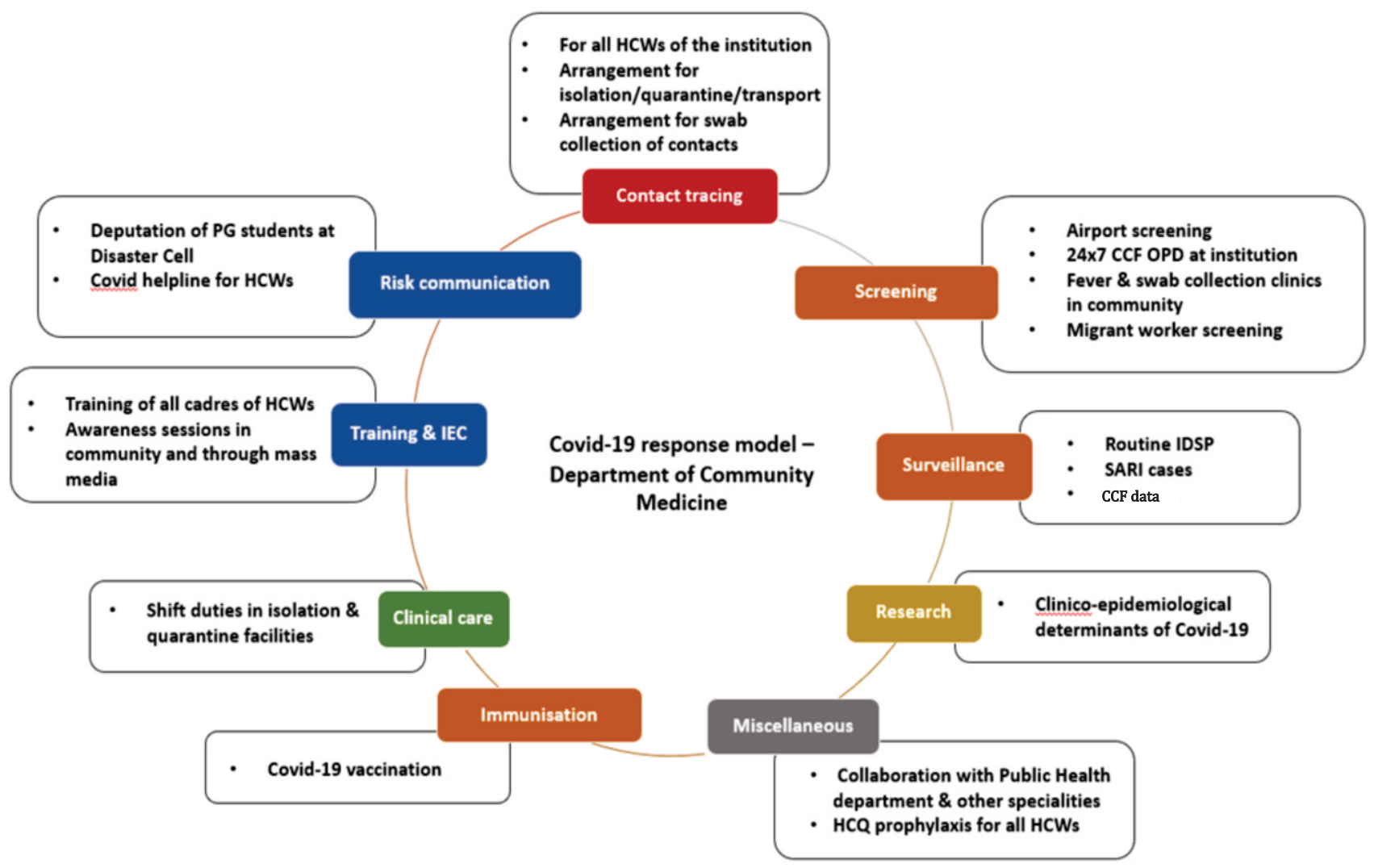

[CCF OPD - Cough-Cold-Fever OPD; HCQ - Hydroxychloroquine; HCWs - Healthcare workers; IDSP - Integrated Disease Surveillance Programme; SARI - Severe Acute Respiratory Illness]

according to the progression of thepandemic. The activities of Community Medicine department is unique to this specialty and has provided a lifetime experience for its residents and faculty. It has provided an opportunity to work beyond specialties in cooperation with other departments. While screening, surveillance, contact tracing are roles that are unique to Community Medicine, we went beyond and performed other administrative and clinical duties. Our purpose here is to project the roles depicted in this model so that some of them can be followed by community medicine departments of other colleges and continued post-pandemic too. We are witnessing a lifetime opportunity to go through large scale experiential learning on containing a pandemic in one of the global hot spots. The relevance and significance of this discipline cannot be overstated during this pandemic. The roles in the aforementioned model would certainly help in widening the perspective of the discipline after the pandemic too.This period has been an eye-opener and will help in strengthening the status of this discipline in the medical field.

\section{Declaration:}

Funding: Nil

Conflict of Interest: Nil

\section{References:}

1. STEWART WH. An American Concept of Comprehensive Care PubMed. Public Heal Rep 1963;78:93-100.

2. Krishnan A. Community medicine in India - Which way forward? Indian J Community Med 2016;41:5-10. doi:10.4103/09700218.170956.

3. Kumar R. Clinical practice in community medicine: Challenges and opportunities. Indian J Community Med 2017;42:131. doi:10.4103/ijcm.IJCM_18_16. 